\title{
$\begin{array}{ll}\text { Research Square } & \text { Preprints are preliminary reports that have not undergone peer review. } \\ \text { They should not be considered conclusive, used to inform clinical practice, } \\ \text { or referenced by the media as validated information }\end{array}$
}

\section{The Impact of an Inpatient Treatment on the Psychodynamic and Symptomatology in Couples Concordant for Substance Use: A Qualitative Study}

\author{
Aksel Hansen \\ Psychiatrische Dienste Thurgau Psychiatrische Klinik Munsterlingen \\ Stefan Brokatzky \\ Psychiatrische Dienste Thurgau Psychiatrische Klinik Munsterlingen \\ Kai Thomas \\ Evangelische Stiftung Tannenhof \\ Christina Sternbauer \\ Psychiatrische Dienste Thurgau Psychiatrische Klinik Munsterlingen \\ Myriam Rudaz ( $\square$ myriam.rudaz@stgag.ch ) \\ Psychiatrische Dienste Thurgau Psychiatrische Klinik Munsterlingen https://orcid.org/0000-0003-0550-3558 \\ Gerhard Dammann \\ Psychiatrische Dienste Thurgau Psychiatrische Klinik Munsterlingen
}

\section{Research}

Keywords: substance use disorder, couples, BSCL, couples therapy, concordant, inpatient treatment, gender differences

Posted Date: January 2nd, 2020

DOI: https://doi.org/10.21203/rs.2.19604/v1

License: (a) (1) This work is licensed under a Creative Commons Attribution 4.0 International License. Read Full License 


\section{Abstract}

Background: Much literature is devoted to describing the psychosocial situation of patients with a substance use disorder and the course of their families and healthy partners. Couples where both partners have a substance use disorder are less well described and even less often studied. Method: This study described the psychodynamic and symptomatology, as measured by the Brief Symptom Inventory (BSI), of five concordant couples treated simultaneously as inpatients at the same specialized substance use disorder ward. Results: The psychodynamic characterization of the couples revealed that the female was often the organizer, whereas the male was either the motivator or the lackey. In addition, the female was often emotionally dependent on the male. Most individuals showed symptom reductions from pre- to post-treatment, although the men seemed to benefit to a greater extent than the women. Moreover, the patients did not necessarily desire couples therapy. Conclusion: Treating couples concordant for substance use together in the same inpatient setting is unusual, but possible. The dynamics of couples in drug rehabilitation should be further investigated taking into account possible gender differences.

\section{Background}

Scientific literature deals mostly with patients who use drugs and have partners who are drug-free [1]. The dynamics and course of a therapy for a couple in which both partners are consuming drugs is sparsely described, although there is evidence that romantic partners show high levels of similarity in terms of substance use. For instance, Pivnick et al. studied 126 women who used methadone. They found that half of the women had partners and that $57 \%$ among these had partners with a substance use disorder [2]. In a similar vein, Low et al. found in 121 married adults with a substance use disorder that more than a third of the spouses also had a lifetime history of a substance use disorder [3]. Intimate partner violence often arises in these couples as a consequence of substance use [4]. Also, the substance use of one partner may promote the maintenance or exacerbation of the problematic behaviour in the other [5]. However, there is also evidence that romantic partners can play a positive role by facilitating desistance from using substances [5]. Understanding the psychodynamic of couples, in which both partners are using drugs and are treated simultaneously at the same ward may help addressing the problem more broadly and offer services accordingly.

In the following, we define couples were both partners have a substance use disorder as concordant [6]. Because the partners in these relationships are substance users and romantically related, we viewed them as co-dependent of a patient with a substance use disorder. The co-dependency concept was rapidly introduced into the literature of Al-Anon, which is a self-help group for relatives of substance-using patients [7]. After examining nine women, Whalen [8] described these co-dependent types: (1) "the wavering wife", (2) "the controller", (3) "the punisher", and (4) "the sufferer". These categories were soon abandoned. One other category, which is widespread amongst therapists, is the "enabler", a person whose actions propagate the patient's alcohol consumption. Here, co-dependent behaviour and behaviour which allows alcohol use were seen as equal [9]. Furthermore, Fischer et al. [10,11] defined co-dependency as a dysfunctional pattern towards others and an extreme focus on other persons, as well as the lack of open expression, and emotions, and an extreme focus on the partnership and its importance. Specifically, the partnership towards the substance-using partner is seen as the lifeblood and as the right to exist [12]. A variety of theories have been proposed to explain the phenomenon of co-dependency. Cermak [13] saw co-dependency as a personality disorder. In contrast, Wegscheider-Cruse [14] assumed that anyone could be co-dependent and thus co-dependency should be classified as a separate clinical entity versus a consequence of reactive behaviour $[9,15]$.

Couples concordant for substance use live in a complicated dyad of care and collusion [16] and are rarely treated together in healthcare. It is even frequently advised not to treat couples at the same time and place [17]. Consequently, there is a scarcity of literature describing the psychodynamic course of treatment for concordant couples and whether they can recover from substance use together. Fals-Stewart et al. [18] examined 87 couples with a substance use disorder and found that the relationship became more unstable with a higher percentage of abstinent days. It could be argued that the drug use may be the common ground serving as a basis of the relationship, especially when the drugs are of the same type, e.g. both partners are using opioids. In that sense, therapy could be seen as an attack on the relationship which could lead to a conscious or unconscious refusal of the therapy or bringing it to an end. Abstinence could also lead to a "wake-up" and to a new evaluation of the partner and the relationship, causing either person to return to drug use or to a break-up of the relationship. Or, in the best case we could hope for, it could lead to a stable relationship because the abstinent person remains a good partner. The therapist may also take into account aggressive countertransference as a consequence of, for example, a ban of romantic relationships on the psychiatric ward, or to a conscious or unconscious attack on the relationship by the therapist. The latter could also lead to a defence by the patient, and thus to an end of the therapy. Possible therapist motives could be envy of the relationship or anger, giving rise to sadistic impulses. As a result, the patients are given punishments, in a more or less gentle and diplomatic way, like partner separation or other sanctions. 
With regard to treatment outcome, a higher degree of education, stable housing, and having children have been found to promote the recovery of patients with a substance use disorder [19]. On the other hand, a significant number of patients have a comorbid personality or affective disorder which complicates the treatment [20]. Furthermore, there is an increased risk for Hepatitis $C$ because it is primarily transmitted through the percutaneous contact with blood, e.g. sharing of needles [21, 22, 23], which my additionally affect treatment outcome. To the best of our knowledge, we are not aware of any study that investigated the outcome of an inpatient treatment in couples concordant for substance use disorder that were treated simultaneously at the same ward. The aim of the current qualitative study was therefore to describe the psychodynamic of theses couples over the course of the treatment as well as changes in the symptomatology before and after the treatment. We hypothesized that treating couples concordant for substance use could have two different impacts. On one hand, the care of the partner may be a supporting force, as the partner is more encouraging towards a stable therapy. On the other hand, the partner's care may include protecting the partner from the "punishment" or control of the therapeutic personnel by lying or by obscuring substance use, which could hinder a successful therapy.

\section{Methods}

\section{Study site}

The study was conducted at the psychiatric hospital of Muensterlingen, which is part of the Psychiatric Services of Thurgovia ("Psychiatrische Dienste Thurgau”/PDT). The PDT provides psychiatric services to Thurgovia, a Swiss canton with approximately 260,000 inhabitants [24]. The PDT consists of multiple outpatient departments, and one hospital in Muensterlingen. The clinic in Muensterlingen has 240 inpatient beds.

Thurgovia is considered to be a more rural canton. However, with major centres like Zurich and St. Gallen in close proximity, it also deals with problems like immigration and illegal substance use. Methadone can be obtained via enrollment in a specialised program, but there is no heroin program available. With 4.8/1000 drug related delinquencies, the incidence is, in comparison with other cantons, rather low [24]. It also has a low unemployment rate and a big industrial sector.

\section{Therapeutic setting}

The specialised substance use ward is open, with a recovery-based approach, a maximum of 15 patients, and a low admission threshold. In addition to detoxification and withdrawal treatment, it also provides psychodynamic psychotherapeutic treatment. All patients are assigned to the same therapy scheme: Regular individual consultations with physicians and nursing personnel, sports therapy, ergotherapy, qualified pharmaceutical treatment, acupuncture by the protocol of the National Acupuncture Detoxification Association (NADA), and various group therapies (e.g., social skills, dialectic-behavioral therapy, addiction education). Moreover, couples therapy is provided by a specialised therapist upon request. The weekly schedule at the ward is shown in Table 1.

Table 1. Schedule from Monday to Saturday for the patients on the specialised substance use ward

\begin{tabular}{|c|c|c|c|c|c|c|}
\hline Time & Monday & Tuesday & Wednesday & Thursday & Friday & Saturday \\
\hline $7.50 \mathrm{am}$ & \multicolumn{6}{|c|}{ Morning circle } \\
\hline \multirow{6}{*}{$\begin{array}{l}8.30- \\
11.45 \\
\text { am }\end{array}$} & $8.30-9.45$ & $9.00-10.00$ & $9.00-10.00$ & $9.00-10.00$ & $9.00-10.00$ & 8.30-11.00 Brunch \\
\hline & Ergotherapy & Psychodynamic & Addiction & Psychodynamic & Social Skills & \\
\hline & & & $\begin{array}{l}\text { education } \\
\text { group }\end{array}$ & & & \\
\hline & $10.00-11.45$ & $10.30-11.30$ & $10.15-11.45$ & $10.00-12.00$ & $10.45-11.45$ & \\
\hline & Medical & Recovery group & DBT group & Interdisciplinary & Mindfulness & \\
\hline & rounds & therapya & therapy & rounds & group therapy & \\
\hline \multirow[t]{2}{*}{$11.45 \mathrm{am}$} & \multicolumn{6}{|c|}{ Lunch } \\
\hline & \multicolumn{6}{|c|}{ Distribution of medication. Vital sign control } \\
\hline \multirow{4}{*}{$\begin{array}{l}13.00- \\
16.30 \\
\text { pm }\end{array}$} & $14.30-16.00$ & $13.30-15.00$ & $13.30-15.00$ & $14.00-14.45$ & $13.00-14.00$ & $12.00-13.00$ \\
\hline & Sport & Trauma & Sport therapy & NADA & Body Dynamic & Weekly reflection \\
\hline & therapy & education & & & group therapy & and perspective \\
\hline & \multicolumn{5}{|c|}{ Individual patient therapy } & \\
\hline \multirow[t]{2}{*}{18.00} & \multicolumn{5}{|c|}{ Dinner } & \\
\hline & \multicolumn{5}{|c|}{ Distribution of medication. Vital sign control } & \\
\hline
\end{tabular}

Note. DBT = Dialectic-Behavioral Therapy. NADA = Acupuncture by the protocol of the National Acupuncture Detoxification Association.

${ }^{\mathrm{a}}$ with a peer employee. 


\section{Participants}

A total of 10 patients (five couples) were hospitalised between August 2013 and November 2014 on the specialised substance use ward and all agreed to participate in the study. All couples were heterosexual and described themselves as a couple. During their hospitalisation, all couples were in a stable relationship, and both members of each couple wanted to be treated for multiple substance use under the diagnosis: "Mental and behavioural disorders due to multiple drug use" (ICD 10: F19.2).

\section{Measures}

Length of partnership, living, and family situation. Patients were inquired about the length of their partnership in years and their living situation (i.e., whether they had housing, either individually or as a couple). They were also inquired about their family situation (i.e., whether they had children and whether they lived with them).

Education. The patients were asked whether they have completed a vocational training.

Diagnoses. Patients were diagnosed by ICD-10 criteria and were asked about the use of the following substances: Alcohol, benzodiazepines, cocaine, heroin, cannabis or other. Also, they were inquired about the age of onset for using substances (excluding tobacco smoking). For personality disorders, a consensus diagnosis was given by all therapeutic personnel, taking into account the previous patient history.

Hepatitis $B$ and $C$. The patients were tested by a standardized serum antibody screening test.

Psychological symptoms. The Brief Symptom Check List (BSCL) was used to measure psychological distress and symptoms. It is a short form of the SCL-90. The German translation by Franke et al. [25] was used, which stems from the "Brief Symptom Inventory" or BSI by Derogatis et al. [26]. It measures the degree of subjective distress during the past seven days. Answers are given on a 5-point Likert scale ranging from "not at all" (0) to "extremely" (4). The scale consists of several dimensions: Somatization, obsession-compulsion, interpersonal sensitivity, depression, hostility, phobic anxiety, paranoid ideation, and psychoticism. Patients were asked to complete the BSCL within two days of admission (pre) and at the time of discharge (post).

Psychodynamic characterisation. Psychodynamic characterisation included conscious and unconscious motives of the choice of the partner; Collusive, regressive and progressive aspects of partnership; Dominance or equality within the couple; Dominant affects, aggression and main defence mechanisms (related to the general level of personality organization); Transferential and countertransferential aspects. Psychodynamic characterisation was done by S. Brokatzky, MD, who was the supervising registrar and a certified specialist in the manualized Transference Focused Psychotherapy (TFP) at the time of data collection [27]. During patients' treatment on the ward, he continuously monitored the patients and kept detailed records on their progress in therapy.

Positive treatment outcome. A positive treatment outcome was attributed when both partners of a couple were transferred into either a longterm treatment facility (i.e., where patients are treated for a minimum of six months with a focus on work and social integration) or were treated as outpatients on the specialised substance use ward.

\section{Results}

\section{Preliminary findings}

Table 2 presents detailed information about demographics, diagnoses, and treatment outcomes for each participant. Mean age of the participants was 29 years (Range: 22 to 40 years; $S D=5.98$ ). All partners declared themselves as a couple. The length of the partnership ranged from 8 months to 3 years $(M=2.35$ years; $S D=0.94)$. The partnerships had no discontinuations before or during the stay. Of the ten patients, three had completed a vocational training. Furthermore three had a stable home situation: Couple 5 had a common apartment, and patient 4W had her own apartment. Only couple 2 had children. They had a ten month old child, who did not live with them, as they were not its legal guardian. In addition, patient $2 \mathrm{M}$ had two children, with whom he had no contact.

All patients smoked and all, except patient 3W (was diagnosed with an alcohol use disorder, although she tried cocaine once) and patient $4 \mathrm{M}$, used multiple substances. Of the ten patients, seven had a psychiatric comorbidity. Among these, six were additionally diagnosed with a personality disorder of the cluster B (DSM IV). All patients tested negative for Hepatitis C and three patients tested positive for Hepatitis B (both members of couple 2, and patient 3M, respectively). 
The length of the stay at the ward ranged from 41 to 235 days $(M=112.3, S D=61.24)$. Only couples 3 and 5 requested specialised couples therapy. None of the couples received any visits by family members, although family visits are allowed and perceived by the therapists as helpful. All participants received further therapy after treatment termination at the ward, with the exception of couple 3 .

Table 2. Information about demographics, diagnoses, and treatment outcomes for each patient

\begin{tabular}{|c|c|c|c|c|c|c|c|c|c|c|c|}
\hline Patient & $\begin{array}{l}\text { Length } \\
\text { of } \\
\text { therapy } \\
\text { in days }\end{array}$ & Age & Comorbidity & $\begin{array}{l}\text { Follow } \\
\text { up }\end{array}$ & Outcome & Education & Housing & $\begin{array}{l}\text { Used } \\
\text { Substances }\end{array}$ & $\begin{array}{l}\text { Length of } \\
\text { the } \\
\text { partnership } \\
\text { in years }\end{array}$ & $\begin{array}{l}\text { Hep } \\
\text { B }\end{array}$ & $\begin{array}{l}\mathrm{Hep} \\
\mathrm{C}\end{array}$ \\
\hline $1 \mathrm{~W}$ & 117 & 29 & None & LT- & + & + & neg & $\mathrm{H}, \mathrm{B}, \mathrm{C}$ & 3 & neg. & neg. \\
\hline $1 \mathrm{M}$ & 113 & 27 & None & $\begin{array}{l}\text { LT- } \\
\text { Therapy }\end{array}$ & + & + & neg & $\begin{array}{l}\mathrm{B}, \mathrm{H}, \mathrm{THC}, \\
\text { Sirdalud }\end{array}$ & 3 & neg. & neg. \\
\hline $2 \mathrm{~W}$ & 94 & 23 & Cluster A/B & $\begin{array}{l}\text { LT- } \\
\text { Therapy }\end{array}$ & + & - & neg & $\mathrm{C}, \mathrm{H}$ & 2 & pos. & neg \\
\hline $2 \mathrm{M}$ & 93 & 35 & Cluster B & $\begin{array}{l}\text { LT- } \\
\text { Therapy }\end{array}$ & + & - & neg & $C, A, H$ & 2 & pos. & neg \\
\hline $3 \mathrm{~W}$ & 235 & 40 & BPD & None & - & + & neg & $A,(C)$ & 3 & neg. & neg. \\
\hline $3 \mathrm{M}$ & 199 & 35 & Cluster B & None & - & - & neg & A, H,C & 3 & pos. & neg. \\
\hline $4 \mathrm{~W}$ & 86 & 25 & & $\begin{array}{l}\text { LT- } \\
\text { Therapy }\end{array}$ & + & + & pos & THC, H, C & 0,75 & neg. & neg. \\
\hline $4 \mathrm{M}$ & 100 & 26 & ADHD & $\begin{array}{l}\text { LT- } \\
\text { Therapy }\end{array}$ & + & - & neg & $\mathrm{H}$ & 0,75 & neg. & neg. \\
\hline $5 \mathrm{~W}$ & 41 & 25 & BPD & None & + & - & pos & $\begin{array}{l}\mathrm{H}, \mathrm{C}, \mathrm{THC}, \\
\mathrm{B}, \mathrm{O}\end{array}$ & 3 & neg. & neg. \\
\hline $5 \mathrm{M}$ & 45 & 22 & $\mathrm{BPD}$ & None & + & - & pos & $\mathrm{H}, \mathrm{B}, \mathrm{A}$ & 3 & neg. & neg. \\
\hline
\end{tabular}

Note. $\mathrm{M}=$ Man. $\mathrm{W}=$ Woman. $\mathrm{BPD}=$ Borderline Personality Disorder. LT-Therapy = Long-term Therapy. ADHD = Attention Deficit Hyperactivity Disorder. Cluster. A/B = Personality Disorder with mixed symptoms from the Clusters A and B (DSM IV). Substances used: $\mathrm{H}=$ Heroin; B = Benzodiazepine, THC = Cannabis; A = Alcohol; O = Other; C = Cocaine. Hep $=$ Hepatitis. Education $=$ Completed a vocational training $(+=$ yes,$-=$ no $)$.

\section{Main findings}

Psychodynamic characterization. In the following, the psychodynamic for each couple over the course of the treatment is described.

Couple 1: The couple behaved like mother and son. The female patient took the lead and organised their social life. During clinical visits, she often spoke for him, which was sometimes due to language problems. Furthermore, she often cut him short during conversations or commented on his ideas as ridiculous. The dominant affects were insecurity and subliminal anger. In countertransference, anger and concern could be felt. She wavered. On one hand, she felt good when she could support him, and on the other hand, she felt burdened because she had to organize everything. He was socially dependent on her, which increased her self-esteem.

Couple 2: The couple seemed very dissimilar. She was the driving force for the treatment, and he seemed like an impediment. She was dependent on his love, tolerated his rude behaviour, and couldn't tell him her opinion. He took advantage of her love, and degraded her when she revolted. The dominant affects were aggression and fear of loss. In countertransference, anger, concern and his wish to save her could be felt. Primarily, she was emotionally dependent on him, whereas he was indifferent and exploitative. In several therapeutic sessions, both claimed that it was their main goal to receive custody of their child again. The couple got engaged after leaving the inpatient therapy.

Couple 3: The couple first seemed very mature, responsible and equal. Over time, it became obvious that she took care of official matters. In a crisis, the roles switched, and he protected her from suicide. During this crisis, it came to a massive confrontation with verbal and physical aggression. The dominant affects were anger and fear of loss. In countertransference, boredom and tiredness, but also pressure, could be felt. He was dependent on her concerning official matters, whereas he was the main motivating factor behind abstinence and treatment motivation. On an emotional level, she was very dependent on him, as he filled her inner void. During their treatment at the ward, they "adopted" a 17-year-old male patient who was alone at Christmas time. The couple separated after being discharged from the ward.

Couple 4: The couple appeared like mother and son. During the clinical visits, the female patient often spoke for both and corrected her partner. Sometimes she also motivated him. Both tried to make their relationship appear harmonious. It was also remarkable that both 
partners tried to euphemise or even repudiate the other's negative aspects. The dominant affects were subliminal anger and fear of loss. In countertransference, boredom and tiredness could be felt. She felt good when she could support him and this bolstered her self-esteem. It seemed that he was dependent on her because she organized everything for him, whereas she was emotionally dependent on him.

Couple 5: The couple appeared and acted like Siamese twins, for whom topics were always the same. If one partner focussed on medication, so did the other. The same could be said about their mood. On the other hand, the partners also had fights, which were characterised by mental and physical abuse. Here, the male partner was submissive. The dominant affects were fury and fear of loss. In countertransference, impotence and anger could be felt. Both enjoyed that during an emotional crisis only the partner could help the other. They celebrated this as a special ability, although they also realized that this made them very dependent on each other.

Follow-up. We were able to follow-up with some patients or relatives 12 months after the discharge from the ward by phone. Couple 1 was still together and raised a family with two children. Both partners of Couple 3 died. The male was found dead, and the female committed suicide. Couple 4 separated.

Psychological symptoms. Table 3 provides the scores of the BSCL at pre- and post-treatment for each patient, except for both partners of couple 5 who did not fill out the questionnaires. Also, patient $2 \mathrm{M}$ did not fill out the questionnaire at post. On the level of the couples, Couple 3 seemed to benefit most with regard to symptom reductions. In couple 2 and 4 the males benefited more than the females. In particular, the men showed reductions on six or more subscales including the global severity index, whereas the women showed increases on four or more subscales as well as on the global severity index. On the individual level, five out of seven patients showed decreases on somatization, interpersonal sensitivity, depression, paranoid ideation, and psychoticism as well as on the global severity index, whereas three out of seven patients showed increases on obsession-compulsion and hostility.

Table 3. Scores of the Brief Symptom Checklist at pre- and post-treatment for each patient

\begin{tabular}{|c|c|c|c|c|c|c|c|c|c|}
\hline Patient & Somatization & $\begin{array}{l}\text { Obsession- } \\
\text { Compulsion }\end{array}$ & $\begin{array}{l}\text { Interpersonal } \\
\text { sensitivity }\end{array}$ & Depression & Hostility & $\begin{array}{l}\text { Phobic } \\
\text { anxiety }\end{array}$ & $\begin{array}{l}\text { Paranoid } \\
\text { ideation }\end{array}$ & Psychoticism & GSI \\
\hline $1 \mathrm{~W}$ & $1.1 / 0.1$ & $1 / 0.5$ & $0.5 / 0.25$ & $1 / 0.5$ & $0.2 / 0.3$ & $0.8 / 0.8$ & $0.8 / 0.2$ & $0.8 / 0$ & $1.4 / 1$ \\
\hline $2 \mathrm{M}$ & 1.4/n.a. & 1.5/n.a. & 0.5/n.a. & 0.7/n.a. & 1/n.a. & 1.7/n.a. & 1.6/n.a. & 1.2/n.a. & 1.3/n.a. \\
\hline $2 \mathrm{~W}$ & $0.29 / 0.5$ & $0 / 0.5$ & $0 / 1.25$ & $0 / 0.33$ & $0.2 / 0.6$ & $0 / 0.6$ & $0.2 / 0.8$ & $0 / 0.4$ & $0.15 / 0.55$ \\
\hline $2 \mathrm{M}$ & $0.14 / 0.29$ & $0.33 / 0$ & $0.5 / 0.25$ & $0.17 / 0$ & $0 / 0$ & $0.2 / 0.4$ & $0.6 / 0.4$ & $0.2 / 0$ & $0.26 / 0.17$ \\
\hline $3 \mathrm{~W}$ & $0.57 / 0$ & $1.17 / 0.17$ & $1 / 0$ & $1.17 / 0.17$ & $0.6 / 0$ & $1.5 / 0$ & $0.4 / 0$ & $0.8 / 0$ & $0.85 / 0.11$ \\
\hline $3 \mathrm{M}$ & $0.57 / 0.29$ & $1.17 / 0.17$ & $1 / 0.25$ & $0.5 / 0$ & $1 / 1$ & $0.8 / 0.6$ & $1 / 0.6$ & $0.8 / 0.4$ & $0.81 / 0.47$ \\
\hline $4 \mathrm{~W}$ & $2.43 / 2.14$ & $2.17 / 2.83$ & $1.25 / 3.25$ & $2.33 / 2.33$ & $2.0 / 3.6$ & $1.8 / 1.4$ & $1.2 / 2.6$ & $2.4 / 2.0$ & $2.04 / 2.53$ \\
\hline $4 \mathrm{M}$ & $2.86 / 2.71$ & $1.33 / 1.83$ & $3 / 1.75$ & $2.17 / 2$ & $2.4 / 2.0$ & $1.8 / 1$ & $1.8 / 1.4$ & $2.2 / 1.6$ & $2.25 / 2.06$ \\
\hline
\end{tabular}

Note. $\mathrm{M}=$ Man. $\mathrm{W}=$ Woman. n.a. = not available. GSI = Global Severity Index.

Table 4 presents the means, standard deviations, and the effects sizes between pre- and post-treatment for women and men separately. For the men, all effect sizes were at least small in size. Large effects were found for decreased interpersonal sensitivity, depression, paranoid ideation, psychoticism, and global severity. For the women the effect sizes were also at least small in size, with the exception of obsession-compulsion and global severity. The largest effect was found for decreased somatization. However it should be noted, that the effects for the women were positive for interpersonal sensitivity, hostility, and paranoid ideation meaning that these symptoms increased.

Table 4. Means, standard deviations, and pre-post treatment comparisons on the symptomatology for women and men separately 


\begin{tabular}{|c|c|c|c|c|c|c|}
\hline \multirow[b]{2}{*}{ BSCL } & \multirow[b]{2}{*}{ Gender } & \multicolumn{2}{|c|}{ Pre } & \multicolumn{2}{|c|}{ Post } & \multirow[b]{2}{*}{ Cohen's $d$} \\
\hline & & $M$ & $S D$ & $M$ & $S D$ & \\
\hline \multirow[t]{2}{*}{ Somatization } & Women & 1.10 & 0.95 & 0.69 & 0.99 & -0.81 \\
\hline & Men & 1.19 & 1.46 & 1.10 & 1.40 & -0.42 \\
\hline \multirow[t]{2}{*}{ Obsession-Compulsion } & Women & 1.09 & 0.89 & 1.00 & 1.23 & -0.11 \\
\hline & Men & 0.94 & 0.54 & 0.67 & 1.01 & -0.37 \\
\hline \multirow[t]{2}{*}{ Interpersonal sensitivity } & Women & 0.69 & 0.55 & 1.19 & 1.48 & 0.37 \\
\hline & Men & 1.50 & 1.32 & 0.75 & 0.87 & -1.50 \\
\hline \multirow[t]{2}{*}{ Depression } & Women & 1.13 & 0.95 & 0.83 & 1.01 & -0.50 \\
\hline & Men & 0.95 & 1.07 & 0.67 & 1.15 & -1.47 \\
\hline \multirow[t]{2}{*}{ Hostility } & Women & 0.75 & 0.85 & 1.13 & 1.67 & 0.41 \\
\hline & Men & 1.13 & 1.21 & 1.00 & 1.00 & -0.58 \\
\hline \multirow[t]{2}{*}{ Phobic anxiety } & Women & 1.03 & 0.80 & 0.70 & 0.58 & -0.37 \\
\hline & Men & 0.93 & 0.81 & 0.67 & 0.31 & -0.53 \\
\hline \multirow[t]{2}{*}{ Paranoid ideation } & Women & 0.65 & 0.44 & 0.90 & 1.18 & 0.27 \\
\hline & Men & 1.13 & 0.61 & 0.80 & 0.53 & -2.89 \\
\hline \multirow[t]{2}{*}{ Psychoticism } & Women & 1.00 & 1.01 & 0.60 & 0.95 & -0.71 \\
\hline & Men & 1.07 & 1.03 & 0.67 & 0.83 & -2.00 \\
\hline \multirow[t]{2}{*}{ GSI } & Women & 1.11 & 0.80 & 1.05 & 1.05 & -0.10 \\
\hline & Men & 1.11 & 1.03 & 0.90 & 1.02 & -1.64 \\
\hline
\end{tabular}

Note. $n=4$ for women. $n=3$ for men. Possible range: 0-4. BSCL = Brief Symptom Check List. $M=$ Mean. $S D=$ Standard deviation. GSI = Global Severity Index.

\section{Discussion}

The present study described the psychodynamic of five couples concordant for substance use disorder as well as their symptomatology from pre- to post-treatment. The psychodynamic characterization revealed a recurring pattern in the couples, namely that the female was the organizer, while the male was either the motivator or the lackey. The female in turn was often emotionally dependent on the male. As we had an open setting, where no drug searches were routinely performed, and were done only in extraordinary circumstances, care, as characterised by Simmons [16], could be identified here as supportive care, in which the partners work together toward a substance-free future. Interestingly, although couple 3 showed (admittedly with the longest treatment duration compared with other couples) most symptom reductions (within both partners) and was described at the beginning of the treatment as the couple that seemed most mature, responsible and equal, this couple had a negative treatment outcome and separated. This paradox result could be interpreted as a form of pseudo-harmony. In addition, Couple 3 was the only couple were only one partner used heroin (the man). In all other couples both partners used heroin. Concerning the symptomatology, it is very interesting, that three important psychopathological items (interpersonal sensitivity, hostility and paranoid ideation) decreased significantly in the group of men, but increased during hospitalization in the women. This may indicate gender specific differences that warrant further research. Perhaps men use the inpatient treatment to stabilize more quickly from psychopathology, while women gain more access to difficult sites. Of course, the question also arises as to whether these differences could have something to do with the moderate request for couple treatment.

On the individual level, most individuals showed reductions on the symptoms, whereas some showed increases on obsession-compulsion and hostility. These increases may indicate that coping with emotions remained difficult. This is not any different from single patient settings, in which similar increases were found [28]. A positive treatment outcome was attributed to the couples if they received further therapy after the stay at the ward, which was the case for all couples, except couple 3.

Regarding the length of the relationships, most couples had been together for two to three years. Although we did not ask the couples directly, perhaps the relationship had become more than a substance use community by then, having survived some critical situations and fights. One could also argue that the relationship either "needs" drug use or it dissolves, as no relationship in the study was longer than three years. In line with this, the discrepancy in substance use in couple 3 may have created problems and finally led to a separation at treatment termination. Interestingly, only two couples asked for couple therapy, although an often-heard sentence used by the couples was: "We have got to do something about this", implying that the couple perceived the drug use as a major impediment in their life.

The present qualitative findings can be seen as initial steps toward a better understanding of the psychodynamic and change of symptomatology of couples concordant for substance use treated simultaneously at the same ward. Future studies may want to explore the lack of family visits or relations and their association with the use of drugs or abstinence in the long-term. Also, it would be interesting to examine possible gender differences when couples concordant for substance use are treated together. In future studies, also other measures, in addition to the BSCL, should be included to assess for instance relationship dynamics, social support, and substance use 
(e.g. Alcohol, Smoking and Substance Involvement Screening Test/ASSIST [29]). Furthermore, the psychodynamic of couples concordant for substance use could be compared to couples were only one partner has a substance use disorder to better understand the specificity and treatment needs of these couples. Finally, it would be interesting to explore the reasons why couples concordant for substance use do not request couple therapy.

\section{Conclusion}

Treating couples in which both partners consume substances, at the same time and in the same setting, is a challenge for the team and the other patients. However, it is possible and the participants benefited from the treatment and showed reduced symptoms at treatment termination, though the effects were larger for the men than for the women. In therapeutic contexts, it may useful to further explore the psychodynamic pattern of emotional or organizational dependence of the partners.

\section{Abbreviations}

BSI: Brief Symptom Inventory

PDT: "Psychiatrische Dienste Thurgau"

NADA: National Acupuncture Detoxification Association (NADA)

BSCL: Brief Symptom Check List

TFP: Transference Focused Psychotherapy

ASSIST: Alcohol, Smoking and Substance Involvement Screening Test

\section{Declarations}

- Ethics approval and consent to participate: Not applicable.

- Consent to publication: All patients consented to the usage and publication of their data.

- Availability of data and material: Available from the first author on request.

- Competing interest: None of the authors have got competing interests.

- Funding: There was no specific funding.

- Authors contributions:

- Hansen initialized, drafted, and reviewed the publication

- Thomas reviewed the publication and gave important input

- Brokatzky interviewed the patients and reviewed the publication

- Sternbauer compiled data and reviewed the publication

- Rudaz calculated the effect sizes and worked on the revision of the publication

- Dammann reviewed the publication and gave final approval

- Acknowledgements:

- We would like to thank the patients, who participated in this study, and to Stefan Zahs, RN, for supporting this paper.

\section{References}

1. Birkeland B, Foster K, Selbekk AS, Høie MM, Ruud T, Weimand B: The quality of life when a partner has substance use problems: a scoping review. Health Qual Life Out 2018, 16:219.

2. Pivnick A, Jacobson A, Eric K, Doll L, Drucker E: AIDS, HIV infection, and illicit drug use within inner-city families and social networks. Am J Public Health 1994, 84:271-4.

3. Low N, Cui L, and Merikangas KR: Spousal concordance for substance use and anxiety disorders. J Psychiat Res 2007, 41:942-51.

4. Foran HM, O'Leary KD: Alcohol and intimate partner violence: A meta-analytic review. Clin Psychol Rev 2008, 28:1222-34. 
5. Rhule-Louie DM, and McMahon, RJ: Problem behavior and romantic relationships: Assortative mating, behavior contagion, and desistance. Clin Child Fam Psych 2007, 10:53-100.

6. Cavacuiti CA: You, me...and drugs-a love triangle: important considerations when both members of a couple are abusing substances. Subst Use Misuse 2004, 39:645-56.

7. Harper J, Capdevila CJ : Codependency: a critique. J Psychoactive Drugs 1990, 22:285-92.

8. Whalen TQ: Wives of alcoholics, four types observed in a family service agency. J Stud Alcohol 1953, 14:632-41.

9. Whitfield CL: Co-alcoholism: Recognizing a treatable illness. Fam Community Health 1984, 7:16-27.

10. Fischer JL, Crawford DW: Codependency and parenting styles. J of Adolescent Res 1992, 7:352-63.

11. Fischer J, Wampler R, Lyness K, Thomas E. Offspring codependency: Blocking the impact of the family of origin. Family Dynamics of Addiction Quarterly 1992, 2:20-32.

12. Morgan Jr JP: What is codependency? J Clin Psychol 1991, 47:720-9.

13. Cermak TL: Diagnostic criteria for codependency. J Psychoactive Drugs 1986, 18:15-20.

14. Wegscheider-Cruse S: Choicemaking: For co-dependents, adult children and spirituality seekers. Pompano Beach, FL: Health Communications; 1985.

15. Capel-Sowder K: On being addicted to the addict: Co-dependent relationships. In Co-dependencv: An emerging issue. Edited by Subby R \& Friel J. Pompano Beach, FL: Healdi Communications; 1984: 19-24.

16. Simmons J, Singer M: I love you... and heroin: care and collusion among drug-using couples. Subst Abuse Treat Prev Policy $2006,1: 7$.

17. Fals-Stewart W, O'Farrell TJ, Birchler GR. Behavioral couples therapy for substance abuse: rationale, methods, and findings. Sci Pract Perspect 2004, 2:30-41.

18. Fals-Stewart W, Birchler GR, Ellis L: Procedures for evaluating the dyadic adjustment of drug-abusing patients and their intimate partners. A multimethod assessment approach. J Subst Abuse Treat 1999, 16:5-16.

19. Sofin Y, Danker-Hopfe H, Gooren T, Neu P. Predicting inpatient detoxification outcome of alcohol and drug dependent patients: The influence of sociodemographic environment, motivation, impulsivity, and medical comorbidities. J Addict 2017; 1-11.

20. Dammann G, Gerber H, Denier N, Schmid O, Huber C, Riecher-Rössler A, Wiesbeck GA, Borgwardt SJ, Gremaud-Heitz DJ, Walter M: The Influence of Comorbid Personality Disorder on Patients in Heroin-Assisted Treatment: Pilot data on Clinical Outcome. Heroin Addict Rel Cl. 2017, 19:57-64.

21. Wandeler G, Dufour JF, Bruggmann P, Rauch A. Hepatitis C: a changing epidemic. Swiss Med Wkly 2015, 145:w14093.

22. Grebely J, Prins M, Hellard M, et al. Hepatitis $C$ virus clearance, reinfection, and persistence, with insights from studies of injecting drug users: towards a vaccine. Lancet Infect Dis, 2012, 12:408-14.

23. Degenhardt L, Peacock A, Colledge S: Global prevalence of injecting drug use and sociodemographic characteristics and prevalence of HIV, HBV, and HCV in people who inject drugs: a multistage systematic review. Lancet Glob Health 2017, 5:e1192-e1207.

24. Bundesamt für Statistik, Neuchâtel 2015, https://www.bfs.admin.ch/bfs/de/home/statistiken/gesundheit/determinanten/illegaledrogen.htm/ Accessed on 11.27.2019

25. Franke GH: BSCL-53. Die Symptom-Checkliste mit 53 Items - Standardform - Deutsches Manual. Göttingen: Hogrefe; 2013.

26. Derogatis LR: Brief Symptom Inventory. Baltimore, MD: Clinical Psychometric Research; 1975.

27. Yeomans FE, Levy KN, Caligor E.: Transference-focused psychotherapy. Psychother 2013, 50:449-53.

28. Holmes J: Termination in psychoanalytic psychotherapy: an attachment perspective. Eur J Psychoanal

29. Group, WHO ASSIST Working: The alcohol, smoking and substance involvement screening test (ASSIST): development, reliability and feasibility. Addiction 2002, 97: 1183-94. 